\title{
Acidic ionic liquids based on phosphonium chloride and metal chlorides - recyclable media and catalysts in the Diels-Alder reaction
}

\author{
Ewa Janus \\ West Pomeranian University of Technology, Department of Organic Chemical Technology, ul. Pulaskiego 10, 70-322 \\ Szczecin, Poland, e-mail: ejanus@zut.edu.pl
}

Acidic ionic liquids based on trihexyltetradecylphosphonium chloride $-\mathrm{P}_{6.66 .14} \mathrm{Cl}$ and six different metal chlorides $\left(\mathrm{YCl}_{3}, \mathrm{YbCl}_{3}, \mathrm{MgCl}_{2}, \mathrm{ZnCl}_{2}, \mathrm{CuCl}_{2}, \mathrm{InCl}_{3}\right)$ were prepared. The molar fraction of metal chloride $\left(\mathrm{X}_{\mathrm{MCl}}\right)$ used for the formation of acidic ionic liquids with $\mathrm{P}_{6.6 .6 .14} \mathrm{Cl}$ was changed in the range from 0.3 to 0.5 . The high catalytic activity in the Diels-Alder reaction of cyclopentadiene and various $\alpha, \beta$-unsaturated carbonyl compounds showed ionic liquids at $\mathrm{X}_{\mathrm{MCl}} \geq 0$.4. In general, the highest product yields and endo:exo ratios were achieved in the acidic ionic liquids formed from $\mathrm{MgCl}_{2}, \mathrm{YCl}_{3}$ and $\mathrm{YbCl}_{3}$. Thermogravimetric analysis suggested that the prepared ionic liquids were thermally stable up to nearly $400^{\circ} \mathrm{C}$. Additionally, they could be reused with only little loss of catalytic activity after the 4th recycle.

Keywords: acidic ionic liquids, Diels-Alder reaction, metal chlorides.

\section{INTRODUCTION}

Reactions catalyzed by the Lewis or Brønsted acids and also by super acids play an important role in the organic technology. The alkylation reactions, isomerization of alkanes and functionalization of aromatic hydrocarbons, for example Friedel-Crafts carbonylation, alkylation or acylation which demand strong and super strong acids are widely used in chemical industry. In these processes the dangerous, volatile acids are often used or acids must be used in equimolar amount and above. Acidic catalysts are usually insoluble or poorly soluble in organic solvents. Ionic liquids have proved to be a good alternative to organic solvents. Acidic catalysts can be easily dissolved in ionic liquids in high concentration. In this way the acidic ionic liquids or homogenous acidic mixtures are formed. Chlorometalate ionic liquids especially those formed from $\mathrm{AlCl}_{3}$ and imidazolium ${ }^{1}$ or ammonium chlorides $^{2}$ were the first acidic systems. They contained $\mathrm{AlCl}_{4}{ }^{-}$and $\mathrm{Al}_{2} \mathrm{Cl}_{7}{ }^{-}$anions and formed super acidic systems with inorganic acids and were used as both solvent and acidic catalysts generating the electrophilic agent in the process. Chloroaluminate ionic liquids were used, for example in the Friedel-Crafts alkylation process of benzene and provided higher yield and selectivity to linear alkylbenzene and made possible to carry out this process with olefins or alkyl chlorides as reactants, ${ }^{\mathbf{1}} \mathbf{2}$. Similar acidic catalytic systems were formed. They were based on the other metal chlorides, such as iron(III) chloride, zinc(II) chloride and imidazolium, pyridinium or phosphonium halogenides ${ }^{3,4,5}$. In those catalytic systems the benzylation of aromatic hydrocarbons ${ }^{4}$, the acetylation of benzene $^{5}$ or Diels-Alder reaction ${ }^{6}$ were carried out successfully. As the merit of using the acidic ionic liquids in comparison to organic solvents, the higher yields and selectivity to the desired product and the simple recovery and reuse of the acidic catalyst have to be emphasized.

In the presented study, new ionic liquids were prepared based on trihexyltetradecylphosphonium chloride, $\mathrm{P}_{\text {6.6.6.14 }} \mathrm{Cl}$. Phosphonium chloride tend to be less prone to thermal decomposition than the salts containing a quaternary nitrogen atom (ammonium, imidazolium, pyridinium $)^{7,8}$. It ensures the stability of an acidic ionic liquids based on phosphonium cation when the reaction is conducted at high temperature or when the reaction products are separated by distillation. Six metal chlorides - yttrium(III) chloride, ytterbium(III) chloride, magnesium(II) chloride, copper(II) chloride, zinc(II) chloride and indium(III) chloride were combined with $\mathrm{P}_{\text {6.6.6.14 }} \mathrm{Cl}$ to form new ionic liquids. To our best knowledge, no data on the synthesis and the use of those ionic liquids has been reported.

\section{EXPERIMENTAL}

\section{Materials}

Trihexyltetradecylphosphonium chloride $\mathrm{P}_{6.6 .6 .14} \mathrm{Cl}$, was purchased from Cytec (Canada). Prior to the use, it was dried at $60^{\circ} \mathrm{C}$ under vacuum for 24 hours to water level below 100ppm. All metal chlorides $\left(\mathrm{YCl}_{3}, \mathrm{YbCl}_{3}, \mathrm{CuCl}_{2}\right.$, $\mathrm{ZnCl}_{2}, \mathrm{MgCl}_{2}, \mathrm{InCl}_{3}$ ) of $99.9 \%$ purity were provided by Aldrich. Cyclopentadiene was obtained by thermal craking of the commercial dicyclopentadiene (Fluka). Dienophiles: dimethyl maleate (96\%), methyl-vinyl ketone (99\%), ethyl-vinyl ketone $(97 \%)$, methyl acrylate $(99 \%)$, ethyl acrylate (99\%), butyl acrylate (99\%) and methacroleine (95\%) were purchased from Aldrich and used without further purification.

\section{Preparation of the acidic ionic liquids}

$\mathrm{P}_{6.66 .14} \mathrm{Cl}(1.558 \mathrm{~g}, 3 \mathrm{mmol})$ was placed in a $16 \mathrm{~mL}$ screwed vial which contained a stir bar. This was heated up to $50^{\circ} \mathrm{C}$, prior to the addition of metal chloride. 1.3 mmol, $2.0 \mathrm{mmol}, 2.5 \mathrm{mmol}$ or $3.0 \mathrm{mmol}$ of metal chloride were added, which corresponded to $0.3 ; 0.4 ; 0.45$ or 0.5 of $\mathrm{X}_{\mathrm{MCl} \times} \cdot \mathrm{X}_{\mathrm{MClx}}$ is the molar fraction of metal chloride in its mixture with $\mathrm{P}_{6.6 .6 .14} \mathrm{Cl}$ used to the formation of acidic ionic liquids. The metal chloride was added in several portions with succeeding portions added when the previous one has been completely dissolved in $\mathrm{P}_{6.6 .6 .14} \mathrm{Cl}$. To assure this the $\mathrm{P}_{6.66 .614} \mathrm{Cl}$-metal chloride mixture was intensively stirred and heated up to $100^{\circ} \mathrm{C}$. The colourless to orange liquids were prepared. 


\section{General analytical procedures}

The ionic liquids were characterized by mass spectroscopy and thermal analysis. Mass spectra were recorded on an Autoflex III MALDI TOF/TOF $200 \mathrm{~Hz}$ mass spectrometer (Bruker). Ionic liquids were diluted with methanol.1 $\mu \mathrm{l}$ samples were deposited into plates which were made in MALDI technology and left to evaporation of the solvent at ambient temperature. Then the measurements were performed in high resolution negative ionisation mode.

The DTA/TG analyses were performed with a F. Paulik - L. Paulik - L. Erdey derivatograph, the MOM Budapest product. Samples of the ionic liquids $(500 \mathrm{mg})$ were placed in quartz crucibles. The measurements were conducted within the temperature range of $20-500^{\circ} \mathrm{C}$, at a constant heating rate of $5 \mathrm{~K} \cdot \mathrm{min}^{-1}$, in the atmosphere of static air.

\section{General procedure for the Diels-Alder reaction}

A portion of acidic ionic liquid prepared as described above was weighed and introduced into a round-bottomed flask of $5 \mathrm{ml}$ in capacity, equipped with a magnetic stir bar. For example when the ionic liquids were prepared at $\mathrm{X}_{\mathrm{MClx}}=0.5$, their quantity was as follows: $0.715 \mathrm{~g}$ of $\mathrm{P}_{6.6 .6 .14} \mathrm{Cl} / \mathrm{YCl}_{3} ; 0.800 \mathrm{~g}$ of $\mathrm{P}_{6.6 .6 .14} \mathrm{Cl} / \mathrm{YbCl}_{3} ; 0.654 \mathrm{~g}$ of $\mathrm{P}_{\text {6.6.6.14 }} \mathrm{Cl} / \mathrm{CuCl}_{2} ; 0656 \mathrm{~g}$ of $\mathrm{P}_{6.6 .6 .14} \mathrm{Cl} / \mathrm{ZnCl}_{2} ; 0.615 \mathrm{~g}$ of $\mathrm{P}_{6.6 .6 .14} \mathrm{Cl} / \mathrm{MgCl}_{2}$ or $0.714 \mathrm{~g}$ of $\mathrm{P}_{6.6 .6 .14} \mathrm{Cl} / \mathrm{InCl}_{3}$. Then dienophile and cyclopentadiene (molar ratio 1:1.5) were introduced. For the above example $10 \mathrm{mmol}$ of dienophile and $15 \mathrm{mmol}$ of cyclopentadiene were used. The concentration of ionic liquid in relation to reactants of DielsAlder reaction was expressed as mol\% of metal to dienophile and was $10 \mathrm{~mol} \%$ in all the experiments. The flask was closed with a rubber septum and placed in a thermostated bath at $25^{\circ} \mathrm{C}$. The course of the reaction was controlled by the GC analysis. The samples of the reaction mixture were taken during the reaction and were directly analysed by gas chromatography. The internal standard method with cyclohexanone as standard was used for the calculation of the product yield. The ratio of endo:exo isomers were calculated based on the peak area of two isomers.

In the recycling experiments when the reaction was completed, the reaction flask was connected to the distillation unit and the product was distilled off directly under vacuum. The residual acidic ionic liquid was then cooled to room temperature and recharged with dienophile and cyclopentadiene. The second and the following runs were conducted in the recycled ionic liquid.

\section{Results and discussion}

Acidic ionic lquids were syntesized by the reaction of trihexyltetradecylphosphonium chloride and six different metal chlorides (Fig. 1). The process was carried out without the solvent, at the temperature of $50-100^{\circ} \mathrm{C}$. The concentration of $\mathrm{MCl}_{\mathrm{x}}$ used for the formation of ionic liquid was expressed as the molar fraction of $\mathrm{MCl}_{\mathrm{x}}\left(X_{\mathrm{MCl}}\right)$ in its mixture with $\mathrm{P}_{6.6 .6 .14} \mathrm{Cl}$ and was changed in a range of 0.3 to 0.5 . All the systems were viscous liquids at ambient temperature.

MALDI mass spectra in negative ionisation mode were obtained for the ionic liquids at molar fraction of metal chlorides $X_{\mathrm{MCl}}=0.5$. For all the ionic liquids the only anionic species detected and identified based on isotope pattern were the respective chlorometalate anions: $\mathrm{YCl}_{4}$, $\mathrm{YbCl}_{4}^{-}, \mathrm{MgCl}_{3}^{-}, \mathrm{CuCl}_{3}^{-}, \mathrm{InCl}_{4}^{-}$or $\mathrm{ZnCl}_{3}^{-}$.

Differential thermal analysis of acidic ionic liquids at $X_{\mathrm{MClx}}=0.5$ showed that those ionic liquids are stable under the atmosphere of static air up to $400^{\circ} \mathrm{C}$. Decomposition temperatures (the onset of the decomposition peak) were between $375^{\circ} \mathrm{C}$ and $405^{\circ} \mathrm{C}$.

The ionic liquids were used in Diels-Alder reaction between cyclopentadiene and different dienophiles (1a$1 \mathrm{~g})$ from the group of $\alpha, \beta$-unsaturated carbonyl compounds (Fig. 2). Norbornane derivatives were the products of that reaction.

The reactants were completely miscible with $\mathrm{P}_{6.6 .6 .14} \mathrm{Cl} /$ metal chloride systems and the reaction mixtures remained homogenous. Additionally, the viscosity of ionic liquids dropped with the added reactants.

Based on the model reaction of cyclopentadiene with dimethyl maleate (1a) the effect of the molar fraction of metal chloride $\left(X_{\mathrm{MCl}}\right)$ in the used acidic ionic liquids on the yield and endo:exo stereoselectivity was studied (Fig. $3 \div 8$ ). The molar fractions of $\mathrm{MgCl}_{2}, \mathrm{YCl}_{3}$ and $\mathrm{YbCl}_{3}$ was varied over a range of 0.3 and 0.5 but the concentration of metal in relation to Diels-Alder reactants was constant and was $10 \mathrm{~mol} \%$ of metal to dienophile. The ionic liquids which were formed from $\mathrm{ZnCl}_{2}, \mathrm{InCl}_{3}$ and $\mathrm{CuCl}_{2}$ were less active in the model reaction. The data for those systems at $X_{\mathrm{MClx}}=0.5$ were given in table 1 .

An increase in the reaction rate resulted from an increase in the molar fraction of metal chloride in the used acidic ionic liquids (Fig. 3, 5 and 7). High yields (70\% to $98 \%$ ) of the product were obtained even over a short reaction time of 10 to 120 mins when the used ionic liquids were formed at $X_{\mathrm{MClx}} 0.4$ or higher. Endo:exo stereoselectivities (Fig. 4, 6 and 8 ) in the model reaction was apparently dependent not only on the molar fraction of metal chloride in the used acidic liquids but also on the nature of the metal ion. The endo:exo ratios in the model reaction of cyclopentadiene with $1 \mathrm{a}$, carried out in the $\mathrm{MgCl}_{2} / \mathrm{P}_{\text {6.6.6.14 }} \mathrm{Cl}$ ionic liquid, were lower than that in ionic liquids formed from $\mathrm{YCl}_{3}$ and $\mathrm{YbCl}_{3}$ at the same molar fraction (Fig. 4, 6, 8). However in the reaction of cyclopentadiene with other dienophiles $(1 \mathrm{~b}-1 \mathrm{~g})$ (Table 1) the acidic ionic liquids based on $\mathrm{MgCl}_{2}\left(\mathrm{X}_{\mathrm{MgCl} 2}=0.5\right)$

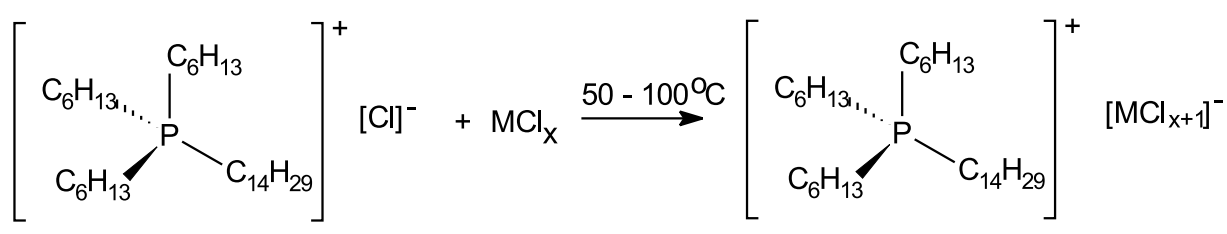


Table 1. The catalytic activity of the $\mathrm{MCl}_{\mathrm{x}} / \mathrm{P}_{6.6 .6 .14} \mathrm{Cl}$ systems in Diels-Alder reaction of cyclopentadiene and different dienophiles*

\begin{tabular}{|c|c|c|c|c|c|c|c|c|c|c|c|c|}
\hline \multirow[b]{3}{*}{ Dienophile } & \multicolumn{12}{|c|}{$\mathrm{MCl}_{\mathrm{x}}$} \\
\hline & \multicolumn{2}{|c|}{$\mathrm{YCl}_{3}$} & \multicolumn{2}{|c|}{$\mathrm{YbCl}_{3}$} & \multicolumn{2}{|c|}{$\mathrm{MgCl}_{2}$} & \multicolumn{2}{|c|}{$\mathrm{ZnCl}_{2}$} & \multicolumn{2}{|c|}{$\mathrm{CuCl}_{2}$} & \multicolumn{2}{|c|}{$\mathrm{InCl}_{3}$} \\
\hline & $\begin{array}{l}W^{1)} \\
{[\%]}\end{array}$ & $S^{3)}$ & $\begin{array}{l}W^{1)} \\
{[\%]}\end{array}$ & $S^{3)}$ & $\begin{array}{l}W^{1)} \\
{[\%]}\end{array}$ & $S^{3)}$ & $\begin{array}{l}\mathrm{W}^{2)} \\
{[\%]}\end{array}$ & $S^{3)}$ & $\begin{array}{l}\mathrm{W}^{2)} \\
{[\%]}\end{array}$ & $S^{3)}$ & $\begin{array}{l}W^{2)} \\
{[\%]}\end{array}$ & $S^{3)}$ \\
\hline Dimethyl maleate & 96 & 11.4 & 95 & 11.3 & 94 & 10.6 & 19 & 3.2 & 28 & 3.0 & 17 & 2.9 \\
\hline Methyl-vinyl ketone & 96 & 17.2 & 97 & 17.0 & 96 & 17.0 & 96 & 13.4 & 94 & 4.8 & 66 & 5.3 \\
\hline Ethyl-vinyl ketone & 97 & 15.2 & 94 & 15.0 & 98 & 16.3 & n.d. & n.d. & n.d. & n.d. & n.d. & n.d. \\
\hline Methyl acrylate & 93 & 9.0 & 91 & 8.9 & 62 & 14.2 & 27 & 4.2 & 19 & 3.7 & 32 & 3.5 \\
\hline Ethyl acrylate & 95 & 8.8 & 92 & 8.6 & 80 & 9.7 & n.d. & n.d. & n.d. & n.d. & n.d. & n.d. \\
\hline Butyl acrylate & 93 & 8.9 & 91 & 9.1 & 85 & 11.0 & n.d. & n.d. & n.d. & n.d. & n.d. & n.d. \\
\hline Methacrolein & 74 & 3.7 & 65 & 3.6 & 78 & 4.2 & 93 & 5.9 & 90 & 10.0 & 15 & 5.6 \\
\hline
\end{tabular}

* molar fraction $\mathrm{X}_{\mathrm{MClx}}=0.5$; concentration of $\mathrm{MCl}_{\mathrm{x}}$ vs dienophile was $10 \mathrm{~mol} \%$; reaction temperature $25^{\circ} \mathrm{C}$

1) Yield of product for 30 minutes

2) Yield of product for 60 minutes

3) stereoselectivity endo:exo

n.d. - not determined;<smiles>C1=C[CH+]C=C1</smiles>

cyclopentadiene<smiles>[R]C([R])=C([R])[R]</smiles>

$1 a-1 g$

Dienophile

$\mathrm{R}_{1}$<smiles>C=C</smiles>

endo<smiles>[R]C1([R])C2C=CC(C2)C1([R])[2H]</smiles>

$\mathrm{R}_{3} \quad \mathrm{R}_{4}$

$\begin{array}{lccccc}\text { 1a } & \text { Dimethyl maleate } & \mathrm{C}(\mathrm{O}) \mathrm{OCH}_{3} & \mathrm{C}(\mathrm{O}) \mathrm{OCH}_{3} & \mathrm{H} & \mathrm{H} \\ \text { 1b } & \text { Methyl-vinyl ketone } & \mathrm{C}(\mathrm{O}) \mathrm{CH}_{3} & \mathrm{H} & \mathrm{H} & \mathrm{H} \\ \text { 1c } & \text { Ethyl-vinyl ketone } & \mathrm{C}(\mathrm{O}) \mathrm{C}_{2} \mathrm{H}_{5} & \mathrm{H} & \mathrm{CH}_{3} & \mathrm{H} \\ \text { 1d } & \text { Methyl acrylate } & \mathrm{C}(\mathrm{O}) \mathrm{OCH}_{3} & \mathrm{H} & \mathrm{H} & \mathrm{H} \\ \text { 1e } & \text { Ethyl acrylate } & \mathrm{C}(\mathrm{O}) \mathrm{OC}_{2} \mathrm{H}_{5} & \mathrm{H} & \mathrm{H} & \mathrm{H} \\ \text { 1f } & \text { Butyl acrylate } & \mathrm{C}(\mathrm{O}) \mathrm{OC}_{4} \mathrm{H}_{9} & \mathrm{H} & \mathrm{H} & \mathrm{H} \\ \text { 1g } & \text { Methacrolein } & \mathrm{CH}_{3} & \mathrm{H} & \mathrm{H} & \mathrm{CHO}\end{array}$

Figure 2. The Diels-Alder reaction between cyclopentadiene and various dienophiles

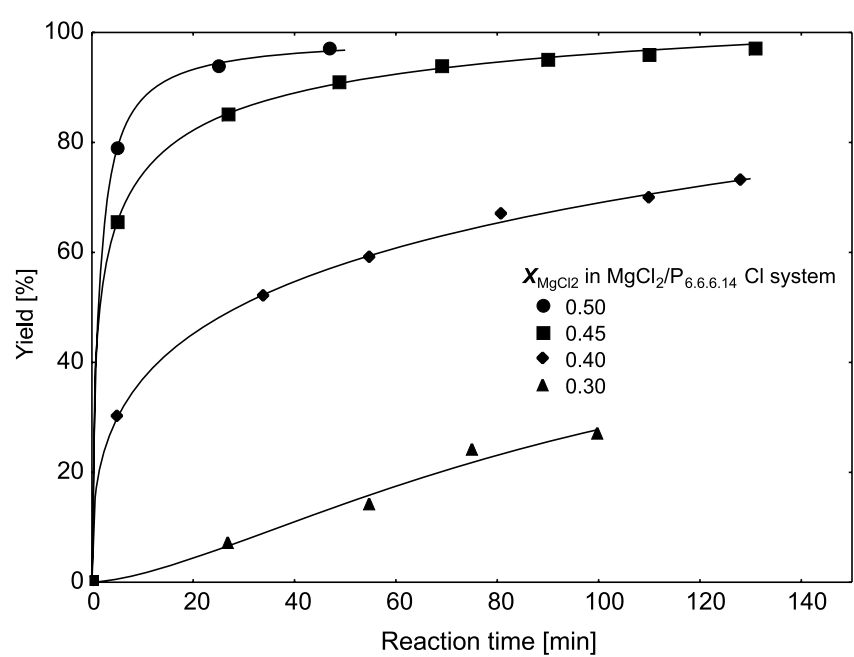

Figure 3. The kinetic profile (dependence of product yield on time) of the reaction of cyclopentadiene and dimethyl maleate at the various $\mathrm{MgCl}_{2}$ molar fraction $\left(\mathrm{X}_{\mathrm{MgCl} 2}\right)$

provided the highest endo:exo ratios. For $\mathrm{MgCl}_{2}$ the progressive increase in endo:exo stereoselectivity from 4.0 to 10.6 with the increase in $\mathrm{X}_{\mathrm{MgCl} 2}$ from 0.3 to 0.5 was

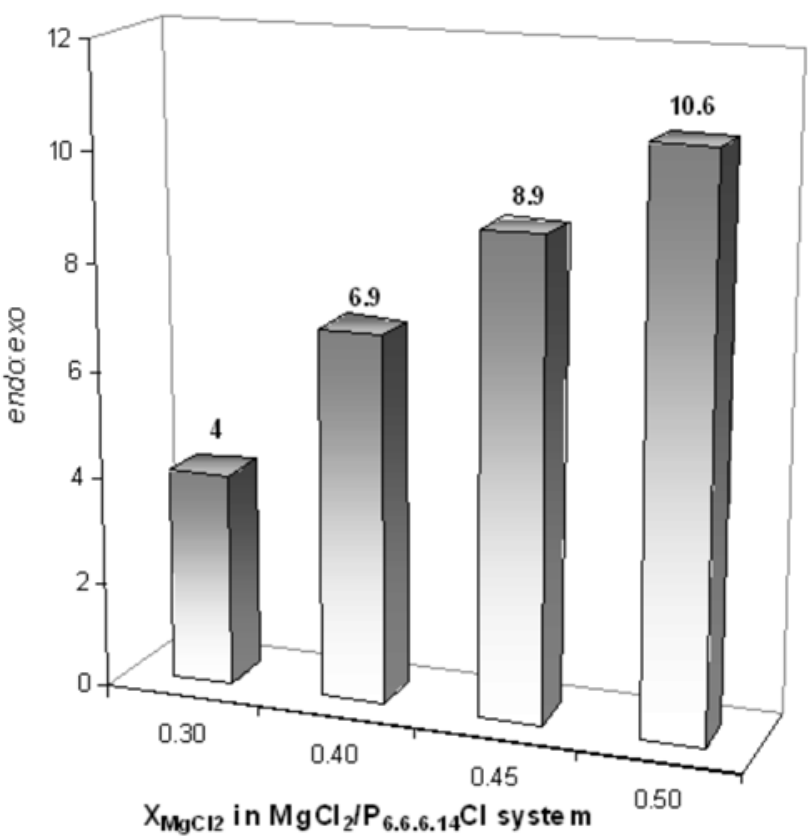

Figure 4. The effect of the $\mathrm{MgCl}_{2}$ molar fraction $\left(\mathrm{X}_{\mathrm{MgCl} 2}\right)$ in $\mathrm{MgCl}_{2} / \mathrm{P}_{\text {6.6.6.14 }} \mathrm{Cl}$ system on the endo:exo stereoselectivity of the reaction between cyclopentadiene and dimethyl maleate 


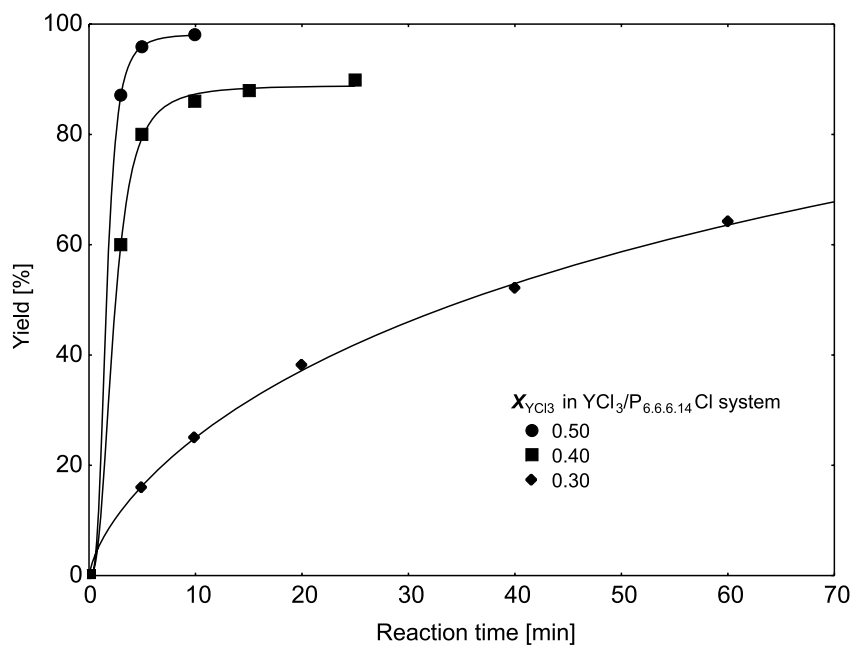

Figure 5. The kinetic profile (dependence of the product yield on time) of the reaction of cyclopentadiene and dimethyl maleate at various $\mathrm{YCl}_{3}$ molar fraction $\left(\mathrm{X}_{\mathrm{YCl} 3}\right)$

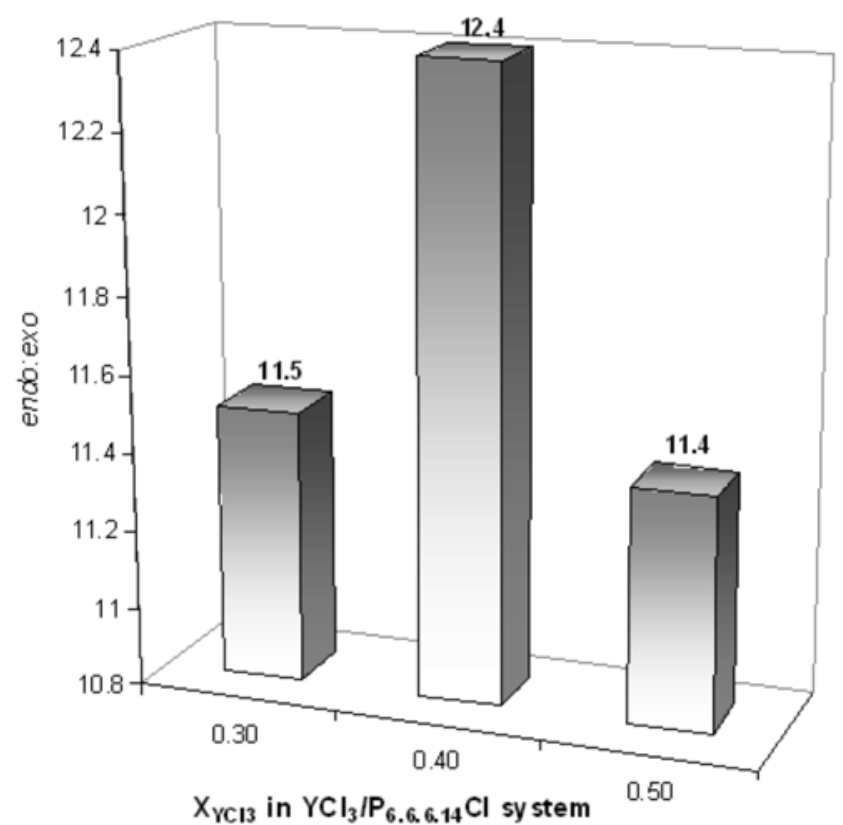

Figure 6. The effect of the $\mathrm{YCl}_{3}$ molar fraction $\left(\mathrm{X}_{\mathrm{YCl} 3}\right)$ in $\mathrm{YCl}_{3} / \mathrm{P}_{\text {6.6.6.14 }} \mathrm{Cl}$ system on the endo:exo stereoselectivity of the reaction between cyclopentadiene and dimethyl maleate

observed whereas in the same range of $X_{\mathrm{YCl} 3}$ and $X_{\mathrm{YbCl} 3}$, the changes of endo:exo were little $-11.4 \div 12.4$ and 10.7 $\div 13.3$ respectively and the best values were provided at molar fraction of 0.4 .

Diels-Alder reaction of cyclopentadiene with different dienophiles were performed in the acidic ionic liquids which were formed at $\mathrm{X}_{\mathrm{MCl}}=0.5$ (Table 1). In general, the highest product yields and endo:exo ratios were achieved in the acidic ionic liquids formed from $\mathrm{MgCl}_{2}$, $\mathrm{YCl}_{3}$ and $\mathrm{YbCl}_{3}$. They provided $90 \%$ yields of the products and high endo:exo stereoselectivities within $30 \div 60$ minutes for each dienophile used except for methacrolein. In the presence of ionic liquids consisted of $\mathrm{ZnCl}_{3}{ }^{-}$and $\mathrm{CuCl}_{3}^{-}$anions, the increase in the reaction yield and endo:exo ratio was only observed in the reaction of cyclopentadiene and methyl-vinyl ketone or methacrolein.

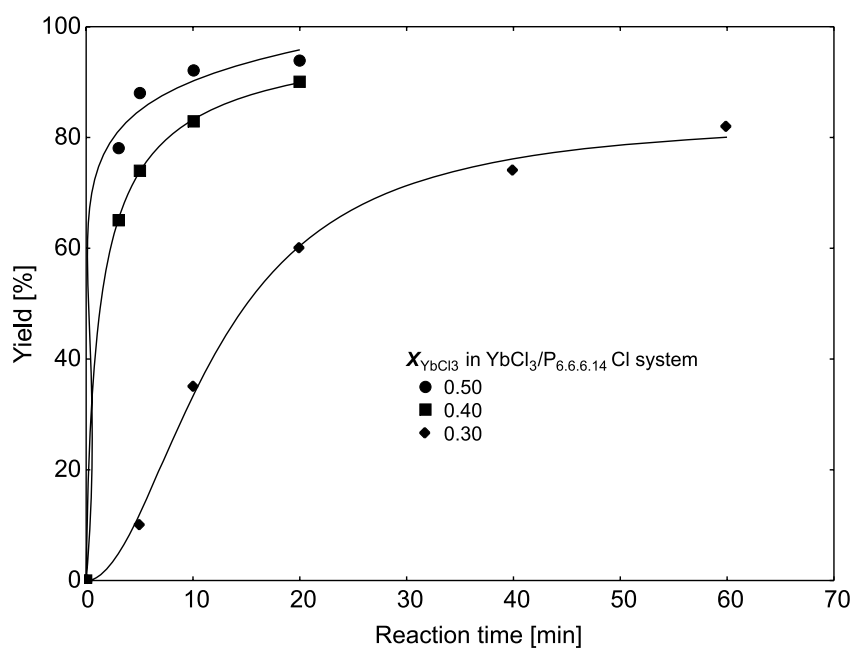

Figure 7. The kinetic profile (dependence of the product yield on time) of the reaction of cyclopentadiene and dimethyl maleate at various $\mathrm{YbCl}_{3}$ molar fraction $\left(\mathrm{X}_{\mathrm{YbCl} 3}\right)$

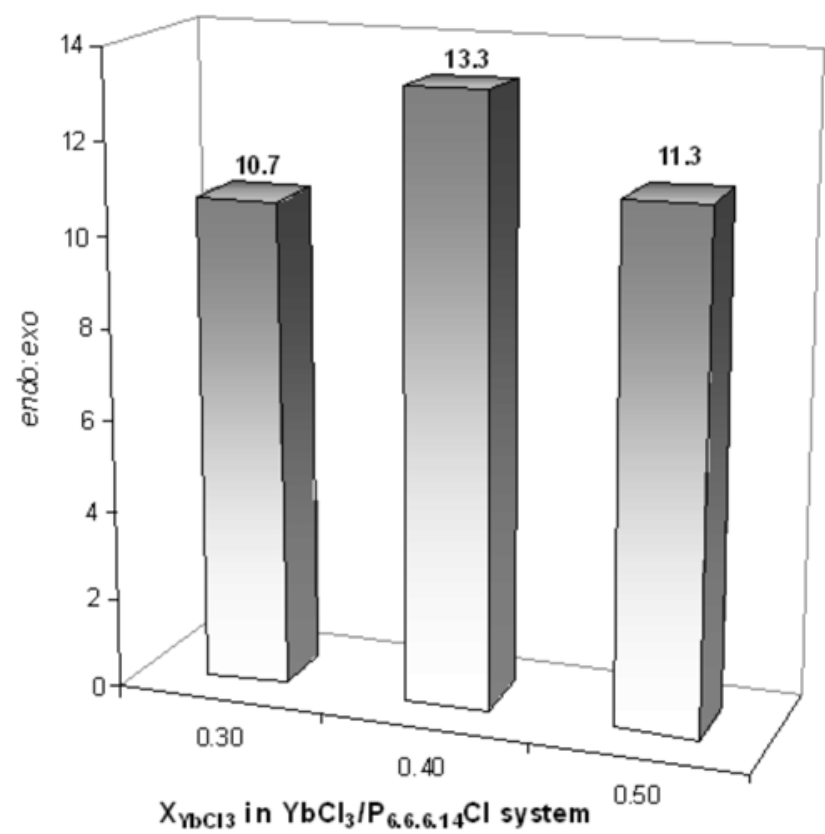

Figure 8. The effect of the $\mathrm{YbCl}_{3}$ molar fraction $\left(\mathrm{X}_{\mathrm{YbCl} 3}\right)$ in $\mathrm{YbCl}_{3} / \mathrm{P}_{\text {6.6.6.14 }} \mathrm{Cl}$ system on the endo:exo stereoselectivity of the reaction between cyclopentadiene and dimethyl maleate

However, ionic liquids based on $\mathrm{InCl}_{3}$, didn't demonstrate the catalytic activity in any studied reaction.

Ionic liquids offer the technological advantage of being recyclable. The relevant studies were performed for the model reaction of cyclopentadiene with dimethyl maleate in the presence of three ionic liquids, which have the highest activity. When the reaction was completed the product was separated from the ionic liquid by distillation under a reduced pressure. The maximum distillation temperature was $160^{\circ} \mathrm{C}$ and it was over $200^{\circ} \mathrm{C}$ higher than the decomposition temperature based on DTA/TG analyses determined. In Fig. 9 the recycle data for systems of $\mathrm{P}_{\text {6.6.6.14 }} \mathrm{Cl}$ with $\mathrm{MgCl}_{2}, \mathrm{YCl}_{3}$ and $\mathrm{YbCl}_{3}$ are presented, where $X_{\mathrm{MCl}}=0.5$.

The formed ionic liquids could be effectively recycled in the reaction and stayed active after fourth recycle. The little drop off in TOF was caused by the inhibition of the 


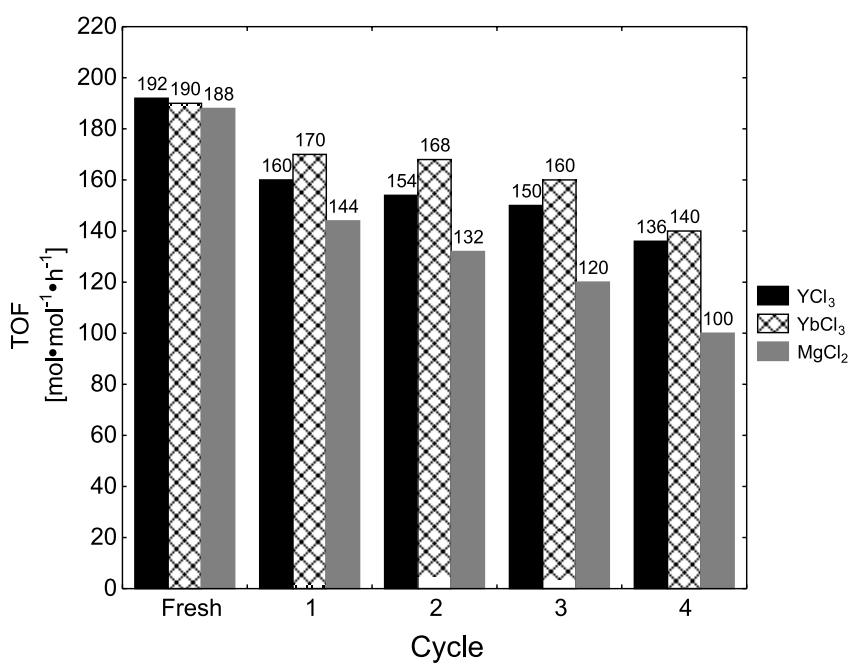

Figure 9. Recycling of the ionic liquids formed from $\mathrm{P}_{6.6 .6 .14} \mathrm{Cl}$ and different metal chlorides (ionic liquids were formed from $0.5 \mathrm{mmol}$ of metal chloride, $0.5 \mathrm{mmol}$ of $\mathrm{P}_{6.6 .6 .14} \mathrm{Cl}$. $5 \mathrm{mmol}$ of dimethyl maleate and 7.5 mmol of cyclopentadiene were added in the following cycles, reaction temperature $25^{\circ} \mathrm{C}$, TOF determined for $30 \mathrm{~min}$.)

catalyst by the product, which was not completely removed from the reaction mixture.

\section{CONCLUSIONS}

The prepared acidic ionic liquids, based on $\mathrm{P}_{6.6 .6 .14} \mathrm{Cl}$ and metal chlorides have proved to be thermally stable up to nearly $400^{\circ} \mathrm{C}$. They consisted of phosphonium cation and the respective chlorometalate anion. The ionic liquids formed at molar fraction of metal chlorides,
$\mathrm{X}_{\mathrm{MCl}} \geq 0.4$, were the effective catalysts of Diels-Alder reaction. They improved the yield, reaction rate and stereoselectivity. Ionic liquids prepared from $\mathrm{YCl}_{3}, \mathrm{YbCl}_{3}$ and $\mathrm{MgCl}_{2}$ have proved to be the most active in the reaction of cyclopentadiene with various dienophiles. They could be reused after removing the product by distillation and remained active after the $4^{\text {th }}$ recycle.

\section{LITERATURE CITED}

1. Abdul-Sada, A. A. K., Atkins, M. P., Ellis, B., Hodgson, P. K. G, Morgan, M. L. M. \& Seddon, K. R. (1995). World Patent No. WO9521806 A1.

2. Sherif, F. G., Shyu, L.J., Greco, C. C., Talma, A. G. \& Lacroix, C. P. M. (1998). World Patent No. WO9803454 A1.

3. Ciao, Y. \& Malhotra, S. V. (2005). Friedel-Crafts alkylation reactions in pyridinium-based ionic liquids. J. Mol. Catal. A 230, 129 - 133. doi:10.1016/j.molcata.2004.12.015.

4. Yin, D., Li, Ch., Tao, L., Yu, N., Hu, S. \& Yin, D. (2006). Synthesis of diphenylmethane derivatives in Lewis acidic ionic liquids. J. Mol. Catal. A, 245, 260 - 265. doi:10.1016/ j.molcata.2005.10.010.

5. Davey P. N., Newman C. P., Seddon K. R. \& Earle M. J. (1999). World Patent No. WO9919288 A1.

6. Abbott, A. P., Capper, G., Davies D. L., Rasheed R. K. \& Tambyrajah, V. (2002). Quaternary ammonium zinc- or tincontaining ionic liquids: water insensitive, recyclable catalysts for Diels-Alder reactions. Green Chem. 4, 24 - 26. doi:10.1039/ b108431c.

7. Tsunashima, K. \& Sugiya, M. (2007). Physical and electrochemical properties of low-viscosity phosphonium ionic liquids as potential electrolytes. Electrochem. Commun. 9, 2353 - 2358. doi:10.1016/j.elecom.2007.07.003.

8. Chowdhury, S., Mohan, R. S. \& Scott, J. L. (2007). Reactivity of ionic liquids. Tetrahedron 63, 2363 - 2389. doi:10.1016/j.tet.2006.11.001. 